\title{
The Relationship between Accounting Information Systems and Making Investment Decisions in the Industrial Companies Listed in the Saudi Stock Market
}

\author{
Qasim Alawaqleh $^{1}$, Mahmoud Al-Sohaimat ${ }^{1}$ \\ ${ }^{1}$ Accounting Department, Faculty of Administrative and Financial Sciences, Philadelphia University, Amman, \\ Jordan \\ Correspondence: Qasim Alawaqleh, Accounting Department, Faculty of Administrative and Financial Sciences, \\ Philadelphia University, Amman, Jordan.
}

Received: March 21, 2017

Accepted: May 16, $2017 \quad$ Online Published: May 22, 2017

doi:10.5539/ibr.v10n6p199

URL: https://doi.org/10.5539/ibr.v10n6p199

\begin{abstract}
The study aimed to measure the relationship between the investment decision-making in the industrial companies listed in the Saudi Stock Market with the (IVs) characteristics of the accounting information systems (appropriateness and reliability, comparability and understanding), and renovation and maintenance of the hardware and software. The problem in the Kingdom of Saudi Arabia is that the government depends on oil revenues more than on attracting investments, therefore, the importance of this study is constituted by the provision of critical recommendations to policy makers in the Kingdom of Saudi Arabia in order to overcome this issue and improve the investments. In order to achieve the objectives of this study, questionnaires were administered to 194 people representing the study population; a multiple regression (standard regression) was also used to test the study hypotheses. In general, all variables were positively significantly related with the investment decision-making.

The findings of this study also showed that the independent variables explained more than $65 \%$ of the variance in investment decision-making. The Saudi government and policy makers should issue new regulations to increase the interest in accounting information systems in order to attract the investment. In relation to the practical and theoretical contribution, this study used new variables in the new model, such as renovation and maintenance of the hardware and software. Furthermore, practical contribution will help policy makers and the Saudi government to advance in this area and implement new policies for investors in order to protect the economy and the society stability due to the war in Yemen and Syria.
\end{abstract}

Keywords: accounting information systems, investment decision-making, capital markets

\section{Introduction}

The Saudi economy depends primarily on oil revenue; this has become inadequate because during the Arab Spring, we know the Saudi economy has been suffering from some financial difficulties because of the financial support to the war in Yemen and Syria. Therefore, the Saudi government have encouraged and invited investors to come to Saudi Arabia to overcome those financial distresses. To address this problem, the government has instated an initiative in order to attract investments.

The Saudi government has recommended and requested from all investment stakeholders, companies, and researchers to seek for consideration and study the act. It is known that the literature related to financial issues plays a significant role in both the academic world and in the popular press. Furthermore, attracting new investments has become an important political economic issue since the increase in the public awareness in Saudi Arabia due to the Arab Spring. Since the Arab Spring and up until today, the re have been little concrete achievements. Regarding this issue, numerous meetings have been held but the attempt to attract investments has been limited, and the financial problems remain unsolved.

The question why the government does not articulate the method to attract new investments remains an issue. Regarding the empirical studies, the information about attracting new investments in the industrial companies listed in the Saudi stock market is still lacking among foreign investors. It is normal that the accountant in the industrial companies listed in the Saudi stock market gives the necessary information to external parties in order 
to attract their investments. Accounting information is of great interest because of its strategic and vital role in supporting all entity activities. It has become a basic requirement in the era of globalization and technological advances and urges most companies to adopt high-quality information technology and lower the costs through advanced technologies in order to help the beneficiaries make different decisions in various economic fields, especially in making investment decisions in an era of severe competition among companies globally and locally, attracting new investments, and preserving existing investments so we can have reliable, accurate, and fair accounting information that meets the stakeholders' needs in various economic fields, especially with regard to investment operations.

Given the importance of information and the de velopment of the traditional accounting systems into information systems, most companies had the tendency to shift from traditional systems to computerized accounting information systems in order to keep pace with the era of speed in communications and information technology so as to obtain information in a timely manner to effectively manage the various activities and communicate the information to beneficiaries through the disclosure of accounting and financial information.

Based on that assumption, this study aims to measure the relationship between the characteristics of accounting information and investment decision-making in the industrial companies listed in the Saudi Stock Exchange in order to help in the investment decision-making process. Finally, the findings of this study contribute to the empirical knowledge towards increasing the responsibility of the Saudi government and policy makers in consolidating the attempt to attract new investments to overcome the financial distress. Also, the study is oriented towards the building of theory and knowledge enhancement in the role of the AIS in attracting new investments.

\subsection{Problem Statement}

The problem is the study of the characteristics of accounting information in order to demonstrate the effectiveness and the quality of the investment decision-making and the responses of the beneficiaries of this information in order to use it in the investment decision-making process in the industrial companies listed in the Saudi Stock Exchange. The problem also lies in knowing the results pertaining to the use of the software of the computerized accounting systems by the investment decision-makers and the access to the real problems faced by the users of the software. To date, and according to the knowledge of the authors, there are no studies that examined the relationship between the investment decision-making processes in the industrial companies listed in the Saudi Stock Market and the renovation and maintenance of the hardware and software. Consequently, the following questions will be raised in order to work out the problem of this study:

1. What is the relationship between the investment decision-making processes in the industrial companies listed in the Saudi Stock Market and the characteristics of the accounting information systems (appropriateness and reliability)?

2. What is the relationship between the investment decision-making processes in the industrial companies listed in the Saudi Stock Market and the characteristics of the accounting information systems (comparability and understanding)?

3. What is the relationship between the investment decision-making processes in the industrial companies listed in the Saudi Stock Market and the renovation and maintenance of the hardware and software?

\subsection{Objectives of the Study}

The research objectives of this study are as follows:

1. To examine the relationship between the characteristics of the accounting information systems (appropriateness and reliability) and the investment decision-making process in the industrial companies listed in the Saudi Stock Market.

2. To examine the relationship between the characteristics of the accounting information systems (comparability and understanding) and the investment decision-making process in the industrial companies listed in the Saudi Stock Market.

3. To examine the relationship between the renovation and the maintenance of the hardware and software and the investment decision-making process in the industrial companies listed in the Saudi Stock Market.

\subsection{Significance of the Study}

The importance of the study lies in its many practical and theoretical aspects and significance for decision-makers. Its practical importance lies in the identification of the computerized accounting information systems and the importance of the characteristics of the investment decision-making process. The theoretical 
aspect took into account the new variable within the awareness of the researchers, such as the update and the maintenance of the hardware and software used in the accounting information system and its importance and effectiveness in the decision-making process. The study is also of great importance for owners and investment decision-makers, such as managers, heads of departments, auditors, accountants, and investors that rely on the output of the computerized accounting system characteristics in making their investment decisions.

\section{Theoretical Framework and Hypothesis Development}

The importance of the accounting information systems lies in providing the appropriate data for the administration to make the right decisions and formulate an appropriate alternative that fits the company in terms of the investment operations in the stock market. The purpose is thus to carry out the company's functions and activities effectively (Romney \& Steinbart, 2016).

The financial accounting data is mostly considered historical on the basis of the statements of the previous events that have occurred in the entity. This information shall be objective, consistent, and periodically audited due to its importance and reliability in the decision-making process (Nihad, Maher \& Hussein, 2011). Mattar (2014) considered the financial analysis as one of the basic pillars of comparability, which is one of the characteristics of the accounting information systems relied upon when comparing the financial statements of the company with previous years or with other companies in the same industry in order to make efficient and quality investment decisions.

Financial ratios are considered as indicators of the strength or weakness of the financial position of the industrial company on which decision-makers can rely when making their investment decisions (Al Johmani, 2010; Al-Rawi, Hekmat \& Hussein, 2005). Based on that assumption, the comparability process shall be based on the evaluation of the corporate performance and financial conditions, which constitutes one of the priorities of the investment decision-making process. Consequently, the main goal of using this feature is to give a clear and fair picture about the credibility and fairness of the financial statements, so that decision-makers can rely on these findings in order to make their investment decisions with regard to this study. Rawi and Najy (2005) showed that there was a serious weakness in the performance of the industrial companies in developing countries due to the lack of the use of appropriate scientific methods in implementing the accounting information systems and upgrading the hardware and software necessary for making investment decisions. Nevertheless, the status of the financial analysis and of the financial ratios as two of the most important accounting information systems in the decision-making process has been confirmed (Tashman, 2004; Munir, 2014). Nader et al. (2006) also confirmed that the reliance on the comparability property as one of the characteristics of the accounting information systems helps the financial manager in the financial decision-making and investment processes, which is considered to be a barometer for the measurement of the performance of the company compared with other companies. In addition to that assumption, Bryan (1997) sought to test the effect of accounting disclosure in accordance with the requirements of the US capital market initialized in the relationship between the accounting information and the investment decisions in the US capital markets.

This study is based on the analysis of the mandatory accounting variables disclosed, such as prices, revenues, costs, future liquidity, capital spending, and future operations. It has been applied on a sample of 250 companies registered in the New York Stock Exchange in 1990. The study also used the multiple regression analysis method and concluded that the disclosure of future operations may assist in the evaluation of the success of the economic units' indicators in the near future. Based on that, the study used the multiple regression method in order to measure the relationship between the independent and dependent variables (making investment decisions in the industrial companies listed in the Saudi Stock Market).

\subsection{The Accounting Information Systems: Definition and Importance}

Turner, Leslie and Andrea (2009) showed that the accounting information system is a set of financial and human resources data in organizations responsible for the preparation and processing of financial information in addition to the information collected from data processing in order to provide them to all administrative levels for the purpose of controlling and planning the various activities of the company and any third party that has common interests with the company. As for the significance of the accounting information system, it revolves around the existence of ready-made programs in accounting applications in companies and how the company chooses the system that substantially corresponds to its various activities. A previous study conducted by Date (2000) showed that the system consists of many different elements strongly correlated with each other in order to carry out the functions required, either in terms of computerized systems or traditional systems. Abdul Razzaq (2003) confirmed that the main objective of the information system is to provide decision-makers with useful information to help them perform their job efficiently. Donald and Wwygandt (2001) stated that the information 
system has three basic components in the production of information that can be relied upon when making decisions. The first is that all economic events and activities should be filled up in the system, known as the input, in order to process this data; the second component involves processing all the input data and making calculations, whereas the third component is known as the output, which is the information needed by the decision-makers in order to reach win-win investments and other beneficial economic processes for the users of financial statements (Marshal,Stainbart, 2012,239; COBIT 4.1, 2007, 10).

\subsection{The General Concept of the Study Variables}

The accounting information characteristics can be illustrated as independent variables in this study as follows (IFAC, 2008):

Comprehensibility: this property requires the ability to understand the accounting information by users who are supposed to have a reasonable level of knowledge in business, economic activities, and accounting. They should also provide clear and understandable financial information which does not entail complexity and difficulty .

Appropriateness: in order to be convenient, the accounting information should be relevant and affect the economic decisions of users by helping them in the evaluation of past events, present and future, or modifying the previous evaluation process. The financial information should predict the performance of an entity in the future and the ability of the entity to cope with any events and unanticipated changes since the users of the accounting information are interested in predicting the future financial performance. The appropriateness of the information is associated with the nature of this information and its relative importance, such as the disclosure of the work sector or of a new geographic sector. The information is considered a material (relative importance) if the omission or misstatement of the information could affect the economic decisions taken by users based on the financial statements (Turner, Leslie \& Andrea, 2009).

Reliability: information must be reliable in order to be useful. It should be free of significant neutral mistakes and relied upon by users, as this refers to transactions and other events, or the rationality of future events. In order to be reliable, the financial information must accurately reflect the financial transactions and other events that have occurred in the entity. The financial information must be in accordance with the economic reality and not with the legal form only. It must be neither biased nor provided in order to inflate assets, revenues, income or to reduce the obligations and expenses. Furthermore, caution must be at a reasonable limit and free of exaggeration. The financial information should also be complete, since any deletion renders it wrong and unreliable, which decreases its suitability.

Comparability: this means that the financial statements are compared with other financial periods for the same company or with the financial statements of another entity for the same period. The users of the accounting information use the comparison in order to make decisions related to investments, finance, follow up the entity's periodical performance and financial position, and compare them with other companies (Hendriksen, Michael \& Eldon, 1992).

\subsection{Study Variables}

The independent variables of this study are represented in the characteristics of the accounting information systems and the update and maintenance of the hardware and software. The dependent variable is represented by making investment decisions in the industrial companies listed in the Saudi Stock Market. In reference to previous studies, this study has shown how the measurement is used in these variables in addition to its most important findings and recommendations.

\subsubsection{Independent Variables}

The independent variables include the characteristics of the accounting information systems (appropriateness and reliability, comparability and understanding). These characteristics are useful for the decision-maker regardless of whether a traditional or a computerized accounting system is used. Furthermore, in order for information to be useful for decision-makers, it must be compatible with the nature of the decisions, the decision model, and the nature and sources of information needed by the investment decision-makers, who must have the ability to analyze and understand this information (Richard, 2001). Shirazi (1990) showed that the efficient decision-making process is based on the useful information through the characteristics of the accounting information. Bodnar, George and William (1995) confirmed that the accounting information characteristics are necessary in order to make investment decisions. Decision-makers face major limitations when using the characteristics of the accounting information systems in order to test the level of importance and conduct the cost-benefit tests. These limitations differ among decision-makers based on their intrinsic characteristics, such as the demographic factors including the education level, awareness, and the size of information available to the 
decision-makers, so that the comprehensibility information is considered as a liaison between the information characteristics and characteristics of its users. Therefore, this study intends to determine whether the independent variables have a significant impact on the investment decision-making.

In light of the questions raised in the problem of the study, the hypotheses are derived from studying the literature. Therefore, many researchers studied the relationship between the accounting information systems and other factors, such as Ogan Yigitbasioglu, (2016), who showed that there is a significant and positive relation between the information system flexibility and the management accounting adaptability and a positive and significant relation with the effectiveness of management accounting. There was also a moderation effect of the ISF on the relation between the IS integration and the adaptability of management accounting. In line with that, Moqbel, Al-Rjoub and Al-Shwiyat (2015) showed that there is a positive effect of the adoption and implementation of the accounting information systems on the improvement of the production costs. In relation to that, Uyar, Haydar and Kuzey (2017) found that the accounting information system (bookkeeping, financial reporting, and the budgeting system) has a positive impact on the corporate governance level. In another body of literature, Ceran, Gungor and Konya (2016) studied the importance of the accounting information system in preventing the crises that were or will be experienced by businesses, the study revealed that the financial information obtained from the accounting information system is very important for the decision-making process of the businesses, and the accounting information system is protected against the financial crises. Additionally, Brandas, Stirbu and Didraga (2013) aimed to develop and test an integrated approach model of risk, control and auditing of the AIS on three cycles of business processes: purchases, sales and cash in order to improve the efficiency of the IT governance. The study confirmed that there is a medium level of risk for each cycle, and the correlation between risk, control and audit in the management information systems, offers the perception of a stable IT environment for the entity. Furthermore, Choe (1996) investigated the direct relationships between the influence factors (user involvement, top management support, user training and education, and context of the IS group) and the performance of the accounting information systems. The significant information reveals that there are significant positive correlations between the performance of an AIS and the influence factors, such as user involvement, capability of the IS personnel and organization size. Moreover, Tan (2016) used a questionnaire in order to examine the impact of the AIS on internal auditors in Turkey. He found that the AIS contributes positively to the work of internal auditors. Therefore, the related hypotheses are proposed:

HP1: There is a positive relationship between the characteristics of the accounting information systems (appropriateness and reliability) and the investment decision-making process in the industrial companies listed in the Saudi Stock Market.

HP2: There is a positive relationship between the characteristics of the accounting information systems (comparability and understanding) and the investment decision-making process in the industrial companies listed in the Saudi Stock Market.

\subsubsection{Renovation and Maintenance of the Hardware and Software}

This variable is (IV): Programs used in the accounting applications: Juma (2016) showed that the ready-made programs in accounting applications are dramatically progressing in terms of quantity and quality. Many of these programs are of different qualities, which have led to a difficulty in making a choice between them and their significance. Juma (2016) confirmed that the cost of the program is the sole determinant for the selection of ready-made programs. When choosing a ready-made program in accounting applications, it must meet the needs of the company, be protected, and viable for development, modification, and maintenance of the services methods. Ready-made programs in accounting applications have many characteristics, such as simplicity of use by the administration, customer service in the input cycle, the number of inputs required for each action, and ease of modification and de velopment of the program in terms of consistency with the company reports, business services, dealing with other programs, in addition to the services provided by the software suppliers. In relation to that, Sha, Wang, Zhuge, Zhang and Liu (2015) aimed to solve hardware/software partitioning problem, such as minimizing the system time, power consumption, or hardware area. Their study shows "the relationship between the qualities of the solution with the number of nodes when the input benchmarks are in tree structure. Since the objective is to minimize the system power consumption, the smaller values represent the better solutions". In addition, Wohleb, Skinner and White (2013) studied the information that may be used to improve the integration of the hardware, software, and technology tools in business/marketing education programs. The result showed there is a significant difference in the use of hardware and technology tools based on the years of teaching experience. Hence, the following hypothesis is proposed:

HP3: There is a relationship between the renovation and maintenance of the hardware and software used in the 
computerized accounting information systems and the investment decision-making process in the industrial companies listed in the Saudi Stock Market.

\subsubsection{Dependent Variable}

The dependent variable in this study is the investment decision-making process in the industrial companies listed in the Saudi Stock Exchange. Previous studies showed a variety of decisions that included the strategic decisions taken by the senior management in several organizations. The dependent variable is related to determining the goals, policies and strategies of the organization, and control of the overall performance of the organization including long-term planning. The tactical decisions are those made by the medium administrative levels, such as the distribution of workers on the organization's departments, and setting of prices. The operational decisions are those made by the lower administrative levels including the conduct of daily operations (buying, selling, and the production process) of a company (Razak, 2015). Many studies (Saleh, 2010; Houari, 2012) confirmed the importance of the information related to the stock market and the accounting information in the economic units, such as trading decisions. Despite the relative advantages achieved by the industrial companies listed in the Saudi stock market in the field of the rationalization of investment decisions, they suffered some shortcomings that impeded their progress. Hossair and Rahman (1997) said that there were many negative determinants facing the securities markets in the developing countries, such as a poor quality of the financial and accounting information in relation to the needs and behavior of the investors and a limited investment awareness in the stock market.

Wright and Ken (1996) studied the impact of accounting information and its importance when making decisions in the stock and capital markets in the United Kingdom. The study relied on the questionnaires sent to a group of executives in order to evaluate the accounting information about increasing the awareness of investors. The study highlighted the importance of accounting information in assisting the investor when making investment decisions in the financial markets.

\section{Research Frame Work and Methodology}

\subsection{Research Framework}

The independent variables of this study are appropriateness and reliability, comparability and understanding, and renovation and maintenance of the hardware and software. The dependent variable is represented by the investment decision-making in the industrial companies listed in the Saudi Stock Exchange. Figure 1 below shows the research framework of the study.

Figure 1. Research Model

Independent variables

$$
\begin{aligned}
& \text { - Appropriateness and reliability } \\
& \text { - Comparability and understanding } \\
& \text { - Renovation and maintenance of the } \\
& \text { hardware and software }
\end{aligned}
$$

Dependent variable

Investment decision-making

Figure 1. Theoretical Framework

\subsection{Research Design}

The basic research design utilized for this study is a survey design. There is one set of data used for collection purposes, namely primary data. The collection of primary data is accomplished using a personal survey instrument. Data is collected from the personal survey instrument (questionnaire) in order to measure the relationship between accounting information systems and making investment decisions in the industrial companies listed in the Saudi Stock Market. This study is strictly designed for correlation rather than causal analyses.

\subsection{Society and the Study Sample}

The study population consisted of investors, managers, heads of departments, accountants, and external auditors in the industrial companies listed in the Saudi Stock Market and number (77) Industrial Co., which was chosen as a random sample, consisted of 300 people representing the study population.

Table 1 shows the ratio of the questionnaires sent to respondents and the percentage of those that returned them back. 
Table 1. Summary of the Response Rates

\begin{tabular}{lc}
\hline Questionnaires administrated & 300 \\
Undelivered & 62 \\
Subjects contacted & 238 \\
No. of Responses & 194 \\
Response rates $(194 / 238)$ & $81.5 \%$ \\
\hline
\end{tabular}

Table 1. Shows the information on the population and the return rates of the questionnaire sent to the sample in the Saudi kingdom. Out of the 300 questionnaires administered, 238 subjects were eventually delivered but only 194 from the sample were received, resulting in a response rate of $81.5 \%$.

\subsection{Data Analysis}

The multiple regression method is used in the hypothesis testing because there are more than two IVS and one DV. Moreover, all variables have used the interval scale.

\subsection{Instrument Reliability}

The researchers relied on previous studies and questionnaires in the instrument development (5 Likert scale used). The instrument experienced several tests, such as instrument reliability and validity. The results of reliability were statistically acceptable as follows:

Table 2. Cronbach's Alpha Test

\begin{tabular}{cc}
\hline \multicolumn{1}{c}{ Variables } & Cronbach's alpha \\
\hline Appropriateness and reliability & $72.6 \%$ \\
Comparability and understanding & $83.5 \%$ \\
Renovation and maintenance of hardware and software & $82.7 \%$ \\
Investment decision-making & $79.7 \%$ \\
\hline
\end{tabular}

The Cronbach's Alpha values range from $72.6 \%$ to $83.5 \%$. Therefore all factors fulfilled the minimum requirement level of reliability.

\subsection{Linearity, Normality and Homoscedasticity Status}

The results confirmed that the distribution of the sample answers was normal and there was a linear relationship between the independent and the dependent variables which was confirmed by the following tests: (scatter plot diagrams and Q-Q plot). This confirms that the sample study was homogeneous with the population study. As for the normal distribution, the researchers relied on the test (Stem \& Leaf), which is apparently a homogeneous form; this shows that the normal distribution of data makes it possible to use the multiple regression method.

\subsection{Criterion Validity}

This type of test examines the relationship between all variables with each other. Hair, Anderson, Tatham, Black and Babin (2007) confirmed that the high correlation of $90 \%$ and above is considered an indicator of a strong internal correlation between the independent variables with each other. A high correlation among the independent variables indicates that the measurement of one variable leads to the deletion of one of them.

Table. 3 the relationship between variables (Pearson correlation)

\begin{tabular}{|c|c|c|c|c|}
\hline & $\begin{array}{l}\text { Appropriateness and } \\
\text { reliability }\end{array}$ & $\begin{array}{l}\text { Comparability and } \\
\text { understanding }\end{array}$ & $\begin{array}{c}\text { Renovation and } \\
\text { maintenance of hardware } \\
\text { and software }\end{array}$ & $\begin{array}{c}\text { Investment } \\
\text { Decisions }\end{array}$ \\
\hline $\begin{array}{l}\text { Appropriateness } \\
\text { reliability }\end{array}$ & 1 & 0.579 & 0.469 & 0.354 \\
\hline $\begin{array}{l}\text { Comparability and } \\
\text { understanding }\end{array}$ & & 1 & 0.453 & 0.254 \\
\hline $\begin{array}{l}\text { Renovation and maintenance } \\
\text { of hardware and software }\end{array}$ & & & 1 & 0.294 \\
\hline Investment Decisions & & & & 1 \\
\hline
\end{tabular}

Table (3) indicates that the statistical results (Pearson correlation) of this study confirm that there is no high correlation among IVs. This test is necessary before the multiple regression procedure (Hair, J. E., Anderson, R. E., Tatham, R.L., Black, W. C. \& Babin, B, J., 2007).

\section{Results}

\subsection{Analysis of the Relationship between the Variables of the Study}

The study used the bivariate analysis in order to test the relationship between two variables; in light of that, the researchers used the Pearson correlation coefficient to measure the linear relationship between the variables; the " 0 " value indicates the absence of a relationship between the variables but the " 1 " value indicates a strong 
positive correlation; and the "-1" value indicates a strong negative correlation between the variables. Therefore, Cohen (1988) confirmed that the interpretation of the strength of the relationship between two variables is as follows:

Table 4. Strength of the relationship between variables

\begin{tabular}{lc}
\multicolumn{1}{c}{ Correlation } & Strength of the correlation \\
\hline $\mathrm{R}=10.0$ to 29.0 or $\mathrm{r}=-01.0$ to -29.0 & Low \\
$\mathrm{R}=30.0$ to 49.0 or $\mathrm{r}=-30.0$ to -49.0 & Medium \\
$\mathrm{R}=50$ to 1 or $\mathrm{r}=-50.0$ to -1 & High \\
\hline Table 5. The level of relationship between the independent variables and the dependent variable \\
\hline \multicolumn{1}{c}{ Variables } & Strength of the relationship \\
\hline Appropriateness and reliability & High \\
Comparability and understanding & High \\
Renovation and maintenance of hardware and software & Medium \\
\hline
\end{tabular}

The results of the correlation analysis showed the level of the relationship between the independent variables and the dependent variable as they appear in Table 5. We note that there are two independent variables (appropriateness and reliability \& comparability and understanding), which have a high correlation with the dependent variable (investment decision-making) but the renovation and maintenance of hardware and software has a medium correlation with Dv.

\subsection{Multiple Regression Coefficient}

The findings of the regression analysis have revealed that comparability and understanding significantly $(\mathrm{p}=0.000)$ influenced the investment decision-making in the industrial companies listed in the Saudi Stock Market. Furthermore, there is a statistically significant $(\mathrm{p}=0.000)$ impact of appropriateness and reliability on investment decision- making in the Industrial Companies Listed in the Saudi Stock Market. In addition, the renovation and maintenance of hardware and software $(p=0.003)$ is statistically significant on the dependent variable. MRA techniques have shown the results clearly by presenting the impact of multiple independent variables as shown in the following results.

Table 6. Coefficients of independent variables

\begin{tabular}{|c|c|c|c|c|c|}
\hline \multirow[t]{2}{*}{ Model } & \multicolumn{2}{|c|}{ Unstandardized Coefficients } & \multicolumn{2}{|c|}{ Standardized Coefficients } & \multirow[b]{2}{*}{ Sig } \\
\hline & B & Std.Error & Beta & $\mathbf{T}$ & \\
\hline Constant & 0.269 & .212 & & 4.995 & 0.463 \\
\hline $\begin{array}{l}\text { Appropriateness } \\
\text { reliability }\end{array}$ & 0.361 & .041 & 0.502 & 6.817 & 0.000 \\
\hline $\begin{array}{l}\text { Comparability and } \\
\text { understanding }\end{array}$ & 0.380 & .030 & 0.528 & 5.488 & 0.000 \\
\hline $\begin{array}{l}\text { Renovation and maintenance } \\
\text { of Hardware and software }\end{array}$ & 0.312 & .017 & 0,427 & 2.517 & 0.003 \\
\hline
\end{tabular}

of Hardware and software

The regression coefficient $(\beta)$ indicates the effect of the independent variables on the dependent variable. Specifically, for each unit change of the independent variable $\mathrm{X}$, there is an expected change equal to the size of $\beta$ in the dependent variable, $Y$. Hence, the regression model is as follows:

$\mathrm{Y}=\dot{\alpha}+\beta 1 \mathrm{X} 1+\beta 2 \mathrm{X} 2+\beta 3 \mathrm{X} 3+\varepsilon$

Where

$\mathrm{Y}=$ investment decision-making

$\mathrm{a}=$ constant

$\mathrm{X} 1=$ appropriateness and reliability

$\mathrm{X} 2$ = comparability and understanding

$\mathrm{X} 3$ = renovation and maintenance of the hardware and software

$\varepsilon=$ random disturbance term (error).

Table 7. Relationship between the investment decision-making and the appropriateness and reliability

\begin{tabular}{lccccc}
\hline \multicolumn{1}{c}{ Model } & B & Std. Error & Beta & t & sig \\
\hline $\begin{array}{l}\text { Appropriateness } \\
\text { and reliability }\end{array}$ & 0.361 & .212 & 0.502 & 6.817 & 0.000 \\
\hline
\end{tabular}

The value of the (appropriateness and reliability) coefficient in the table above was (0.361). This is a positive sign indicating the existence of a positive relationship between the investment decision-making, as an increase 
in the appropriateness and reliability leads to the increase of the investment decision-making and vice versa. Moreover, the value of possible significance reached (0.000) in Table (7) and it is lower than the level of significance (0.05). Thus, it is accepted that there is a statistically significant relation between the dependent variable pertaining to investment decision-making and the independent variable concerning appropriateness and reliability.

Table 8. Relationship between the investment decisions making and comparability and understanding

\begin{tabular}{|c|c|c|c|c|c|}
\hline Model & B & Std. Error & Beta & $\mathbf{t}$ & sig \\
\hline $\begin{array}{ll}\text { Comparability } & \text { and } \\
\text { understanding } & \end{array}$ & 0.380 & .030 & 0.528 & 5.488 & 0.000 \\
\hline
\end{tabular}

The value of the coefficient of the (comparability and understanding) reached (0.380) and the positive sign is indicative of the existence of a direct relation between the investment decision-making and the comparability and understanding factor, as an increase in comparability and understanding leads to the increase of the investment decision-making and vice versa. Moreover, the value of the possible significance reached $(0.000)$ in Table (8) and it is lower than the level of significance (0.05). Thus, it is accepted that there is a statistically significant relation between the dependent variable pertaining to investment decision-making and the independent variable comparability and understanding.

Table 9. Relationship between the investment decision-making and renovation and maintenance of the hardware and software

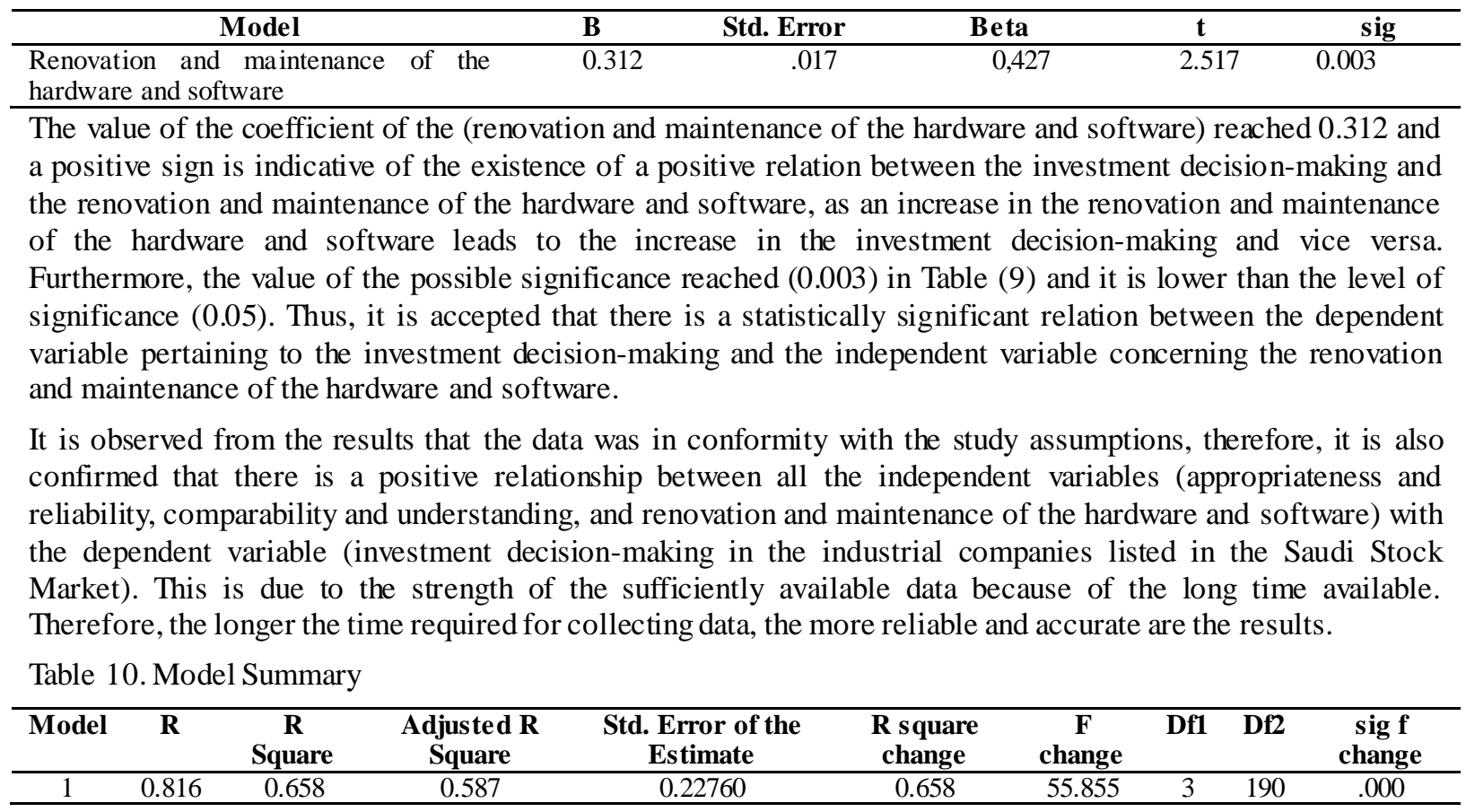

a. Predictors: (constant), appropriateness and reliability, comparability and understanding, and renovation and maintenance of the hardware and software

b. Dependent Variable: investment decision-making

It is clear that the value of the overall correlation coefficient is $\mathrm{R}=81.6 \%$. The correlation coefficient is revealed for the independent variables (appropriateness and reliability, comparability and understanding, and renovation and maintenance of the hardware and software) and the dependent variable (investment decision-making). It is indicated that the existence of a direct and strong correlation between the dependent and independent variables is closer to one (81.6\%). It is noted that the value of the determination coefficient $\mathrm{R}$ square is equal to $65.8 \%$; and the value of the adjusted determination coefficient is $58.7 \%$. The coefficient of determination is referred to as the amount of the explained variance by the regression model, which makes it beneficial as a measure of predicting success (Nagelkerke, 1991). 
Table 11. Analysis of Variance (ANOVA)

\begin{tabular}{lccccc}
\hline \multicolumn{1}{c}{ Model } & Sum of Squares & Df & Mean Square & F & Sig. \\
\hline Regression & 14,482 & 3 & 4.827 & 55.855 & $000(\mathrm{a})$ \\
Residual & 9.825 & 190 & 0.052 & & \\
Total & 24.307 & 193 & & & \\
\hline
\end{tabular}

a. Predictors: (constant), appropriateness and reliability, comparability and understanding, and renovation and maintenance of the hardware and software

b. Dependent variable: investment decision-making

The value of the possible significance reached $(0.000)$ and it is lower than the value of significance $(0.05)$. Thus, the relation is significant, which explains a significant percentage in the dependent variable (investment decision-making).

\section{Discussion}

The relationship between accounting information systems and making investment decisions as applied in the industrial companies listed in the Saudi Stock Market for the year 2016 and 2017 is revealed through the multiple regression. The relationship played by the characteristics of the accounting information system and renovation and maintenance of the hardware and software are emerged in the economies internationally. Therefore, these IVs have proved their ability to achieve a number of economic objectives, and they will also provide investment opportunities that will support the Saudi economy. Governments have focused on encouraging young people to establish small businesses and encourage foreign investments to secure solutions to support the Saudi economy. The data of the variables concerning this study were obtained from investors, managers, heads of departments, accountants, and external auditors. The variety of regression data provides appropriate results in accordance to the hypothesis. All study results were important because of the presence of a strong direct correlation between the dependent variable (investment decision-making) and the independent variables (appropriateness and reliability, comparability and understanding, and renovation and maintenance of the hardware and software). Therefore, the value of the correlation coefficient $\mathrm{R}$ and the value of the determination coefficient $\mathrm{R}$ Square indicated that the independent variables affect the dependent variable by $65.8 \%$. There is a direct relationship between the IVs and DV.

Over the past few years, Saudi Arabia has worked hard in order to embark effective strategies that support the initiation of small businesses that would help to meet the needs for the economy growth of the country. For starting up a successful investment, the knowledge of the characteristics of the accounting information system and the renovation and maintenance of the hardware and software will help to attract good investments. Saudi Arabia needs for efficient investment policies for the economic improvements in order to cope up with the financial distress because of the war in Yemen and Syria. In line with that, Elimam (2017) indicates that in 2010 Saudi Arabia started new investments related to the entrepreneurship. The characteristics of AIS and renovation and maintenance of the hardware and software are supporting the existence of foreign markets and foreign sources for investments in the industrial companies listed in the Saudi Stock Market, which will contribute to the success and growth of the Saudi economy. Saudi Arabia has built an integrated mining town on the Arabian Gulf coast with investments of $\$ 130$ billion and equipped industrial cities in various regions of Saudi Arabia. Furthermore, and in a second phase, Saudi Arabia was interested in assigning a greater role to the private sector in leading the economy and directing production. This is because the country's economic policy seeks to reduce the dependence on the government sector in terms of creating jobs and creating an economy based on efficiency, if oil prices remain at around $\$ 50$ a barrel or less (Middle East Arabe Newspaper, 2017). Nevertheless, Rahman (2017) examined the determinants of foreign direct investments in the Kingdom of Saudi Arabia. The study used empirical methods and conventional regression models, and the results show the Gross Domestic Product (GDP) levels effect on Foreign Direct Investment (FDI) in a strong, positive and significant way. Also, exports had a significant negative impact on the KSA's FDI, while the socio-political risk variables were mostly significant, and negative in their impacts on the FDI inflows.

Supporting the economy in the Saudi kingdom is largely associated with investments through the existence of big and small business. The major cause for this assertion is that large and small businesses are the basis of revenues, budgets and the extent of the workforce (Elimam, 2017). The contribution of the characteristics of the accounting information system and the renovation and maintenance of the hardware and software towards attracting investments is observed through the existence of a strong statistical relationship between them. Therefore, the results also revealed the existence of an awareness towards the importance of the accounting information systems and renovation and maintenance of the hardware and software by the investment 
decision-makers, which was confirmed by previous studies (Bryan, 1997; Bodnar, George \& William, 1995; Ceran, Gungor \& Konya, 2016; Juma ,2016; Abdul Razak, 2015; Wright \& Ken, 1996).

Moreover, the results showed that the use of comparability and the understanding characteristic has a positive impact on the investment decision-making. This characteristic has a statistically significant effect at $\alpha \geq 0000$, which means that it is considered one of the most influential independent variables on the dependent variable. The more this characteristic of comparability and understanding is used, the better the quality of the investment decisions to be made, which means that the non-use of this characteristic leads to lower quality and inefficiency of the investment decision-making in the industrial companies listed in the Saudi Stock Market.

Obviously, this study also found that there is a statistically significant positive relationship between appropriateness and reliability between an independent variable and the dependent variable (investment decision-making). The more this independent variable is used when making investment decisions, the stronger and more efficient these decisions will be, which means that the non-use of this IV leads to lower quality and inefficiency of the investment decision-making in the industrial companies listed in the Saudi Stock Market.

In line with that, the results of this study showed that the renovation and maintenance of the hardware and software have a positive impact on the investment decision-making process in the industrial companies listed in the Saudi stock market; this impact has a statistically significant relationship at level $\alpha>012$. This variable is one of the most influential variables on the dependent variable, which facilitates a frequent update and maintenance of the hardware and software and makes it possible to keep abreast of the technological developments related to accounting information systems. Thus, the investment decision-making process in the industrial companies listed in the Saudi Stock Market will be more efficient.

Finally, the use of all independent variables together will contribute to a useful and efficient investment decision-making process.

\section{Recommendations}

The need to take all the characteristics of the accounting information systems into account when making investment decisions since these characteristics entail an effective contribution towards ensuring efficient investment decision-making. Indeed, these characteristics contributed to a $65.8 \%$ rate in improving the quality of decisions.

Conducting specialized courses for decision-makers to identify the nature and importance of the accounting information systems necessary for making high-quality investment decisions.

Urging the industrial companies listed in the Saudi Stock Market to use flexible software for the development and changes in the surrounding environment of the company.

Publishing the accounting information and making it available for investors in the Saudi Stock Market by urging the industrial companies to publish summaries about their financial statements including the significant accounting information affecting the investment decision-making.

The researchers recommend future studies to consider other variables because this study contributed to about $65.8 \%$ and left $34.2 \%$ of the rates for other variables that have an impact on the dependent variable (investment decision-making).

The necessity to activate the role of the Saudi Government to attract the investments by spreading awareness through the use of the characteristics of accounting information systems.

The necessity to find a way to implement the regulations, which state that the government encourages and attracts investments.

\section{Limitations}

The sample of the study was initially constituted of 300 respondents and only 196 respondents were received. Therefore, future research should attempt to incorporate a larger sample size in order to increase the generalizability of the results. Additionally, this study assumed that respondents do not consciously or unconsciously represent the truth. This limitation may have affected the findings, since it is based on survey data and may be subject to investments desirability bias. In addition to the investments desirability bias (consciously or unconsciously the respondent wishes to create a favorable impression), the agreement bias (the respondent tends to agree with all questions and deliberate falsification are common types of respondent error in survey studies) should also be taken into consideration (Zikmund, 2000). Even if the study has selected the samples according to a random probability sampling, a random probability error is still unavoidable (Zikmund, 2000). Hence, the samples may have been biased because the particular groups surveyed may have been from the same 
policy-makers, thus it would be expected that they would have similar responses. The second limitation relates to the quantitative approach adopted in this study and does not depend on the other approach, such as the qualitative approach.

\section{References}

Abbas, S. (1990). Accounting Theory. Kuwait: Dar Alsalasel for Publishing.

Abdul, R. Q. (2015). Computerized accounting information systems. Amman: International House of Scientific Publishing and Distribution.

Al-Rawi, H., \& Naji, H. (2005). The use of financial ratios in the decision-making: process in the Industrial Companies of public shareholding in Jordan. Journal of administrative, 10(1).

Bodnar, H., \& William, H. (1995). Accounting Information System, Englewood Cliffs: Prentice-Hall.

Brandas, C., Stirbu, D., \& Didraga, O. (2013). Integrated Approach Model of Risk: Control and Auditing of Accounting Information Systems. Informatica Economică, 17(4). https://doi.org/10.12948/issn14531305/17.4.2013.08

Ceran, M., Gungor, S., \& Konya, S. (2016). The Role of Accounting Information Systems in Preventing the Financial Crises Experienced in Business. Economics, Management, and Financial Markets, 11(1), 294-302.

Choe, J. M. (1996). The Relationships among Performance of Accounting Information Systems: Influence Factors, and Evolution Level of Information Systems. Journal of Management Information Systems, 12(4), 215-239. https://doi.org/10.1080/07421222.1996.11518107

Cohen, J. (1988). Statistical Power Analysis for the Behavioral Sciences (2nd ed.) Mahwah. NJ: Lawrence Erlbaum Associates.

Date, J. (2000). An Introduction to Database Systems, Seven Edition, Melbourne: Addison-Wesley Publishing Company.

Elimam, H. (2017). The Role of Small Business (Small Scale Economic Projects) in Alleviating the Acuity of Unemployment. International Business Research, 10(3). https://doi.org/10.5539/ibr.v10n3p120

Hair, J. E., Anderson, R. E., Tatham, R. L., Black, W. C., \& Babin, B. J. (2007). Multivariate Data Analysis. Washington: Pearson Prentice Hall International Inc.

Hendrickson, S. E., \& Michael, F. V. B. (1992). Accounting Theory, Fifth Edition, Irwin: McGraw-Hill.

Houari, S. M. (2012). Financial management: Approach to decision-making. Aim Shams: Ain Shams Library.

International Federation of Accountants (IFAC). (2008). Handbook of International Auditing, Assurance, and Ethics Pronouncements.

IT Governance Institute (ITGI), (2007). Executive Summary COBIT 4.1, www.itgi.org.

Johmani, O. I. (2010). The extent of accurate of financial ratios in the prediction of fail banks: A field study on the Jordanian banking sector, Journal of Public Administration.

Juma, H. (2016). Accounting Information Systems: Applied contemporary.

Kieso, E. D., Jerry, J. W., \& Warfield, T. D. (2015). Intermediate Accounting, 22 editions, 2015.

Marshall, R. (2002). Accounting Information Systems, 8th Edition, New Jersey: prentice-Hall, Inc.

Mattar, M. (2014). Recent trends in the financial and credit analysis: Methods and tools and scientific uses. Amman: Wael for Publishing.

Middle East Arabe Newspaper. (2017). Saudi investments continue to boost economic stimulus, No.14039. (http://aawsat.com/home/article/812996).

Mike, W., \& Robbie, K. (1996). Venture capitalists, unquoted equity investment appraisal and the role of accounting information. Accounting and Business Research, 153-168.

Moqbel, A., \& AL-Shwiyat, Z. (2015). The Effect of Applying Accounting Information Systems on the Improvement of Production Costs: An Applied Study on Jordanian Industrial Firms Listed on the Amman Stock Exchange. International Management Review, 11(2).

Munir, S. (2014). Financial Analysis entrance to the decision-making. Amman: Dar Wael for Publishing.

Nader, M., \& Hussein, J. (2006). Study of financial indicators and their role in administrative decision-making 
field study on cotton yarns company in Lattakia. Tishreen University Journal for Studies and Scientific Research, 28(3).

Nagelkerke, J. (1991). A note on a general definition of the coefficient of determination. Biometrika, 78(3), 691-692. https://doi.org/10.1093/biomet/78.3.691

Nihad, N., Maher, A., \& Hussein, J. (2011). Study of financial indicators and their role in management decisions. Tishreen University Journal for Studies and Scientific Research, 33(8).

Ogan, Y. (2016). Firms information system characteristics and management accounting adaptability. International Journal of Accounting and Information Management, 24(1), 20-37. https://doi.org/10.1108/IJAIM-10-2014-0066

Qassem, A. (2004). Analysis and Design of Information Systems. Pyongyang: House of Culture for Publishing.

Rahman, A. (2017). Determinants of Foreign Direct Investment in the Kingdom of Saudi Arabia. Department of Economics, Riyadh: King Saud University.

Romney, B., \& Paul, S. (2012). Accounting Information Systems (12th ed). New Jersey: Prentice-Hall, Inc.

Romney, B., \& Paul, S. (2016). Accounting Information Systems (13th ed). New Jersey: Prentice-Hall, Inc.

Saleh, E. (2010). The role of accounting data in financial market in Saudi Arabia. Journal of scientific commerce.

Schroeder, R., Myrtle, C., \& Jack, C. (2001). Accounting Theory and Analyses, New Jersey: John Wiley \& Sons, Inc.

Sha, E., Wang, L., Zhuge, O., Zhang, J., \& Liu, J. (2015). Power Efficiency for Hardware/Software Partitioning with Time and Area Constraints on MPSoC. Int $J$ Parallel Prog, 43, 381-402. https://doi.org/10.1007/s10766-013-0283-4

Stephen, B. (1997). Incremental information content of required disclosures contained in management discussion and analysis. Accounting Review, 285-301.

Tan, F. (2016). Impact of Accounting Information Systems on Internal Auditors in Turkey. Marmara Üni versitesi Öneri Dergisi.

Tashman \& Diana (2004). The extent of the use of financial ratios in the investment decision-making by Jordanian banks and insurers: A field study, Master Thesis, Yarmouk University / Irbid, Jordan.

Turner, L., \& Weickgenannt, A. (2009). Accounting Information Systems: Control and Processes. New Jersey John Wiley \& Sons, Inc.

Uyar, A., Haydar, A., \& Kuzey, C. (2017). Impact of the Accounting Information System on Corporate Governance: Evidence from Turkish Non-Listed Companies. AABFJ, 11(1). https://doi.org/10.14453/aabfj.v11i1.3

Woelfel, C. (1994). Financial Statement Analysis: The Investor's Self-Study Guide to Interpreting and Analyzing Financial Statements, Revised ed. Probus, Chicago, II.

Wohleb, C., Skinner, L., \& White, J. (2013). Hardware, Software, and Technology Tools in the Business Education Classroom. The Journal of Research in Business Education, 2.

Zikmund, W. G. (2000). Business Research Methods (6th ed). London: the Dryden Press, Harcourt College Publishers.

\section{Copyrights}

Copyright for this article is retained by the author(s), with first publication rights granted to the journal.

This is an open-access article distributed under the terms and conditions of the Creative Commons Attribution license (http://creativecommons.org/licenses/by/4.0/). 